\title{
A study on the effect of organizational trust on learning organizations
}

\author{
Belal Panahi*
}

Faculty Member, Department of management, Payam Noor University, PO BOX 19395-3697 Tehran, Iran

\section{H R O N I C L E}

Article history:

Received June 4, 2014

Accepted 12 October 2014

Available online

October 282014

Trust

Learning

Learning organization

\begin{abstract}
A B S T R A C T
Creating and maintaining a learning organization is a competitive advantage, which would be the result of valuable outcomes such as innovation, efficiency and the better convergence with environment. In addition, learning is the best way to preserve life, survival and growth of organizations in future. In this regard, this study examined the relationship between trust and learning organizations. This study had one main hypothesis and five sub-hypotheses. Research method was descriptive, and t-test and correlation tests were used to determine the relationships between variables. The statistical populations of this study were employees and faculty members of Payam Noor University in east Azerbaijan province, Iran. The results of this study show that there was a meaningful and positive relationship between trust in organization and learning organizations. Therefore, it is recommended that organizations dismantle the barriers of trust, be promoted the trust-builder interactive relationships; be improved and be promoted the mechanisms of interpersonal communications. The firms also have to develop competencies, empower and promote the spirit of cooperation. On the other hand, organizations must prioritize the fostering and promoting the strategic and interactive thinking of staff.
\end{abstract}

2014 Growing Science Ltd. All rights reserved.

\section{Introduction}

Nowadays, there have been tremendous changes on business environment and there is a need to make some changes on structures of organizations. There are new organizational designs in the world such as, virtual organization, Cross-bureaucratic organizations, professional organizations, learning organizations, horizontal organizations, etc. Therefore, today's organizations with traditional structures do not have necessary power and flexibility to align with the peripheral changes because of globalization and its consequences. They have to make changes on their organizational structures for survival or equip themselves with necessary tools to acquire the ability for tackling with global changes and developments. One of the most important tools is to institutionalize organizational learning process and to create a "learning organization" (Nekooie-mogaddam and Beheshtifar, 2006). The only source of strength and survival for organizations in the changing current era is learning better and faster than competitors; because, learning is the key and the main factor for organization

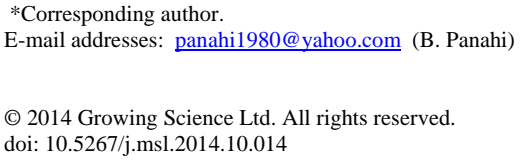


that would be remained in the new world economic and competitive environment (Sharifi \& Eslamiyeh, 2008). In addition, learning is the vital road for recognition and adaption to the increasing speed of change (Marquardt, 2008). Constantly changing and adapting are the elements that form learning organizations. Preparing learning environment and increasing the competency and capability of human resources are necessary for creating a learning organization.

According to researchers, desirable organizations in the future will be learning organizations. Organizations that create opportunities for responsibility, learn from experience, take risks, are satisfied from the results, and learned lessons. The philosophy of such organizations is that in situations where environmental change is rapid, they have more flexibility and adaptability and in competition field will be superior to others. Therefore, organizations to deal with such situations require an understanding of the how exploit from commitment and competence of individuals to learn at all levels of the organization. Organizations that continue to develop their capacity for creating desirable future have to transfer new thoughts and ideas among members. According to Senge (1996), learning enables people to do creativity. Therefore, for learning organization, the stability and survival is not enough. In such organizations, learning is the public and permanent concerns and its slogan is humility in learning and generosity in education.

The main value in learning organization is problem solving, so that employees and members of organizations would be able to solve their problems. These organizations try to increase the value by identifying new needs (Nekooie-mogaddam \& Beheshtifar, 2006). On the other hand, to realize learning in organizations, a suitable environment is needed. This requires a fundamental change in the organizational culture, organizational climate, Breeding patterns of communication and modification of mental models and attitudes of employees. It is considered that actual learning influences in the heart and mind and is caused to the awareness and change in behavior. However, one of the major obstacles in achieving learning organizations is associated with lack of trust, which is the main concern of this study.

\section{Overview on the Theoretical Foundations}

\subsection{Definition of learning organization and its dimensions in the study}

Senge (1996), the main theorist of the learning organization believes that today's organizations must capable of coping with continuous changes in their pursuit of success. In other words, organizations must become learning organizations (Rahmanseresht, 2007). These organizations must be able to learn faster than competitors must in order to maintain competitive advantage as an integrated entity; because faster and better learning is the only thing that can place firms ahead of other competitors in the new century. According to Senge (1996), learning organization is an organization that must be learned within, because learning has been institutionalized as a part of its life (Marquardt, 1996). Before definition of learning organization, it is essential to define the concept of organizational learning and to explain the differences between different concepts. The concept of organizational learning has developed before learning organization. Researchers' serious work on organizational learning has result to emerging concept of organizational learning. Learning has been focused increasingly among organizations that are going to gain competitive advantage, innovation and effectiveness. Argyris and Schon (1995) define organizational learning as "the detection and correction of errors". According to Fiol and Lyles (1985), organizational learning is the process of improvement actions through the better knowledge and understanding. Dodgson defines organizational learning as methods that organizations create, alter and organize until adapt and develop knowledge and normal work activities within culture and also improve efficiency through the use of broader skills of their workforce (Dodgson, 1993). 
The main thing which is coming into view in a review of definitions for organizational learning is that organizational learning directly defined within organization in new perspectives. The main reason for this development is emerging the theory of learning organization in recent years. Precisely the definitions of organizational learning and learning organization are closely related together from this stage. Marquardt explains difference between two terms "organizational learning" and "learning organization" as "The focus in Discussion about learning organization is on the nature and we examined Systems, fundamentals and characteristics of organizations that learn and produce as a collective identity". On the other hand, the nature of organizational learning refers to how learning organization occurs and includes use of knowledge, skills and process of production (Marquardt, 1996). According to Dodgson (1993) learning organization is the firm that help improve organizational learning by creating proper structures and strategies. Also, according to Garvin (1993) learning organization is a firm that has the ability to create, acquire and transfer of knowledge and adjust its behavior with new perspectives (Garvin, 1993: 80). According to Nekooie-mogaddam and Beheshtifar (2006), the foundations of a learning organization are:

- Clear mission and vision that is supported;

- Shared leadership and mental involvement of all people in participative decision making;

- Transfer of knowledge in throughout the organization;

- Experience of organizational culture;

- Promote teamwork and Group work.

Senge (1992) proposed five fundamental principles to create a learning organization, all of the five major principles must be considered related and connected to each other as a whole. Team learning is a prerequisite for systemic thinking; the learning occur at individual, team and organizational levels when mental models are known and shared models are formed. Therefore, the learning occurs with faster when personal, teams and organizational insights are linked together (Rahnavard, 1999). Therefore, the most important components of a learning organization are Personal Mastery, Mental model, Team Learning, shared vision and systemic thinking.

\subsection{Barriers to learning and learning organizations}

Barriers and inhibitors of learning organizations not only can act individually or in group level, but also they are effective in the organizational and structural level. It is difficult to perform the learning organization theory in practice especially when these types of changes will be implemented in large enterprises. In general, an organization cannot be a learning organization unless it is converted into an educational and training system. To achieve this goal, executives have to share their thoughts and ideas with strategies, goals, etc. In general, there are two categories of individual and organizational barriers that impede from creation and development of a learning organization.

\subsubsection{Individual barriers}

Unconscious assumptions "I know everything that I need to know";

Be concern about expressing ideas and opinions in mind;

Be concern about to learn a new skill;

Lack of learning about what worked in the past but was not very effective;

Feeling busy;

More intellectual laziness;

\subsubsection{Organizational barriers}

Manage decisions, which are not questionable; 
Inability or failure to understand the obstacles;

To have critical culture in steed of responsibility culture;

Environment that does not promote to question and to compete or to oppose with it strongly;

The term "knowledge is power" will block contribution in learning;

Believe to "Here is not a place for innovation";

According manager who says, "Our inferiors must learn not us";

Organizations that inhibit mutually participation;

Lack of time, materials and resources for training;

Satisfaction with current situation;

Inability to encourage innovation;

Lack of knowledge about abilities and partnerships;

Lack of appropriate mechanisms to transfer or to develop knowledge (Lawrence, 1998).

\subsection{Trust-based culture necessary to learning organizations}

In recent times that distrust and suspicion are governed to many people, unfortunately, few organizations can pride to quality proper team, trust and cooperation in their cultures. Managers should know how to build and strengthen trust between two or more people, People need to learn how experience and understand the trust of other people, groups or organizations and how it grows between individuals or groups over time (Panahi, 2009). Trust is one of the fundamental aspects of the knowledge-based culture. Employees will be skeptical about the intentions and behavior of each other without a high degree of mutual trust among themselves, and therefore they do not share their knowledge with each other. Creating trust-based relationships among individuals and groups will help considerably facilitate knowledge sharing processes. People participate more in the process of knowledge sharing, when trust increases in relationships among individuals. One of the most important barriers to knowledge sharing is lack of trust among employees. Knowledge sharing is caused to create knowledge by mutual trust. Davenport and Prusak (1998) argued that trust has a positive impact on the flow of knowledge. In addition, trust is one of the major factors influencing on the leadership effectiveness, employee satisfaction, organizational commitment and performance.

Organizational trust is very important in organizations and firms that may conflict or inconsistency between the workers and outsourcing causes to reduce trust in relationships between managers and staff (Fazel et al., 2011). Organizational trust is divided into individual trust and non-individual trust (institutional trust); individual trust is based on the interaction and occurs by specific communication (Fairholm, \& Fairholm, 2000). This type of trust is divided into the horizontal trust (trust between employees) and vertical trust (trust between employees and managers). Individual trust is also based on competency, benevolence and reliability. Non- Individual trust, is based on the roles, systems and understood budgets in order to ensure employees (Atkinson \& Butcher, 2003). In fact, institutional trust is confidence of organizational members to the strategy and organization's business and technical competencies and trust to organizational structures, processes and human resource policies. Institutional trust is connected significantly with employees' attitudes (e.g., organizational commitment) (Fairholm \& Fairholm, 2000).

\subsection{Background Investigations}

Harvey and Denton (1999) researched opportunities for improvement organizational learning in large companies. Their results showed that the element of organizational learning is necessary for changes in the business environment. Also, competitive culture, encourage new ideas; risk-taking, and employee participation in decision-making are key factors in learning process. Ellinger et al. (2000) focused on the effect of learning organization on organizational performance. Sharman (2005) reported that leadership in a learning organization was very different from leadership in traditional 
organization. Hsieny (2004) in his study included that the conclusion that faculty members were more focused on their growth and development factors in organization.

\section{Methodology and Measures}

The method used in this study was a descriptive survey and Correlation test was used to evaluate hypotheses. Data collected by questionnaire for the study. The population was staff and faculty members of Payam Noor University in East Azerbaijan, Iran. The population includes 700 people and 280 subjects were selected, randomly. The main variables were trust and the learning organization. The study used the five-dimensional model of the learning organization proposed by Senge (1992). There are five components, which are necessary to create organizational learning; including selfdevelopment (personal mastery), mental models, team learning, shared vision, systemic thinking. This study used Learning Organization questionnaire developed by Neefe (2001) and consists of five dimensions and 24 items. The reliability of learning organization questionnaire investigated with using SPSS software and Cronbach's alpha was obtained as 0.82. The four dimensions of integrity, dependability, competence, organizational commitment were used for organizational trust (Shafieai, 2011). Organizational trust has 16 items in this questionnaire. The reliability of organizational trust questionnaire was 0.89 in this study. This study has one main hypothesis and five sub-hypotheses as follows:

Main hypothesis: There is a significant relationship between trust and learning organization.

Sub-hypothesis 1: There is a significant relationship between trust and Personal Mastery.

Sub-hypothesis 2: There is a significant relationship between trust and mental models.

Sub-hypothesis 3: There is a significant relationship between trust and Shared Vision.

Sub-hypothesis 4: There is a significant relationship between trust and team learning.

Sub-hypothesis 5: There is a significant relationship between trust and systemic thinking.

\section{Data analysis}

Results of T-Test show that all variables and parameters were higher than standard mean, and between the dimensions of learning organization, systemic thinking had the highest average and all dimensions were accepted significantly. In addition, between the dimensions of organizational trust, organizational commitment had the highest average. Table 1 and Table 2 summarize the results.

\section{Table 1}

One-Sample Test on learning organization

\begin{tabular}{lccc}
\hline Variables & $\mathrm{t}$ & Mean & Sig. (2-tailed) \\
\hline Learning organization & 13.560 & 3.4254 & .000 \\
Systemic thinking & 14.852 & 3.4958 & .000 \\
Team learning & 8.327 & 3.3370 & .000 \\
Shared Vision & 11.818 & 3.4384 & .000 \\
Mental models & 12.727 & 3.4694 & .000 \\
Personal Mastery & 8.456 & 3.3570 & .000 \\
\hline
\end{tabular}

Table 2

One-Sample Test on Organizational trust

\begin{tabular}{lccr}
\hline Variables & $\mathrm{t}$ & Mean & Sig. (2-tailed) \\
\hline Organizational trust & 5.772 & 3.2708 & .000 \\
Organizational commitment & 8.075 & 3.4520 & .000 \\
Competence & 4.587 & 3.2428 & .000 \\
Dependability & 4.883 & 3.2432 & .000 \\
Integrity & 2.457 & 3.1381 & .015 \\
\hline
\end{tabular}


The results of the correlation coefficient tests between trust and learning organizations, and between dimensions of learning organization and organizational trust showed that Correlations were positive and significant at the $99 \%$ level. The correlation between trust and learning organization was 0.73 , which shows there was a strong relationship between these two variables. In addition, the correlations between all dimensions of learning organization and organizational trust were positive and statistically significant. The shared vision of learning organization has more correlation with organizational trust. The results have been summarized in Table 3.

\section{Table 3}

The summary of the results of correlation coefficient tests

\begin{tabular}{|c|c|c|c|c|c|c|c|c|}
\hline Variables & test & $\begin{array}{l}\text { Personal } \\
\text { Mastery }\end{array}$ & $\begin{array}{l}\text { Mental } \\
\text { models }\end{array}$ & $\begin{array}{l}\text { Shared } \\
\text { Vision }\end{array}$ & $\begin{array}{c}\text { Team } \\
\text { learning }\end{array}$ & $\begin{array}{l}\text { Systemic } \\
\text { thinking }\end{array}$ & $\begin{array}{c}\text { Learning } \\
\text { organization }\end{array}$ & Trust \\
\hline \multirow{2}{*}{$\begin{array}{l}\text { Personal } \\
\text { Mastery }\end{array}$} & Correlation & 1 & $.683^{* *}$ & $.558^{* *}$ & $.443^{* *}$ & $.459^{* *}$ & $.754^{* *}$ & $.472^{*}$ \\
\hline & Sig. (2-tailed) & & .000 & .000 & .000 & .000 & .000 & .000 \\
\hline \multirow{2}{*}{$\begin{array}{l}\text { Mental } \\
\text { models }\end{array}$} & Correlation & $.683^{* *}$ & 1 & $.612^{* *}$ & $.549^{* *}$ & $.630^{* *}$ & $.844^{* *}$ & $.580^{*}$ \\
\hline & Sig. (2-tailed) & .000 & & .000 & .000 & .000 & .000 & .000 \\
\hline \multirow{2}{*}{$\begin{array}{l}\text { Shared } \\
\text { Vision }\end{array}$} & Correlation & $.558^{* *}$ & $.612^{* *}$ & 1 & $.593^{* *}$ & $.651^{* *}$ & $.837^{* *}$ & $.659^{* *}$ \\
\hline & Sig. (2-tailed) & .000 & .000 & & .000 & .000 & .000 & .000 \\
\hline \multirow{2}{*}{$\begin{array}{c}\text { Team } \\
\text { learning }\end{array}$} & Correlation & $.443^{* *}$ & $.549^{* *}$ & $.593^{* *}$ & 1 & $.646^{* *}$ & $.802^{* *}$ & $.557^{*}$ \\
\hline & Sig. (2-tailed) & .000 & .000 & .000 & & .000 & .000 & .000 \\
\hline \multirow{2}{*}{$\begin{array}{l}\text { Systemic } \\
\text { thinking }\end{array}$} & Correlation & $.459^{* *}$ & $.630^{* *}$ & $.651^{* *}$ & $.646^{* *}$ & 1 & $.841^{* *}$ & $.630^{*}$ \\
\hline & Sig. (2-tailed) & .000 & .000 & .000 & .000 & & .000 & .000 \\
\hline \multirow{2}{*}{$\begin{array}{c}\text { Learning } \\
\text { organization }\end{array}$} & Correlation & $.754^{* *}$ & $.844^{* *}$ & $.837^{* *}$ & $.802^{* *}$ & $.841^{* *}$ & 1 & $.726^{*}$ \\
\hline & Sig. (2-tailed) & .000 & .000 & .000 & .000 & .000 & & .000 \\
\hline \multirow[t]{2}{*}{ Trust } & Correlation & $.472^{*}$ & $.580^{* *}$ & $.659^{* *}$ & $.557^{* *}$ & $.630^{* *}$ & $.726^{* *}$ & 1 \\
\hline & Sig. (2-tailed) & .000 & .000 & .000 & .000 & .000 & .000 & \\
\hline
\end{tabular}

Sub-hypothesis 1: The relationship between trust and Personal Mastery

As illustrated in Table 3, there is a positive correlation between trust and Personal Mastery. Therefore, because P-value $=0.000<0.05, r=0.47$ the hypothesis is confirmed. The scatter plot between two variables indicates that there was a positive and significant relationship between trust and personal mastery.

Sub-hypothesis 2: The relationship between trust and mental models

As illustrated in Table 3, there is a positive correlation between trust and mental models. Therefore, because P-value $=0.000<0.05, \mathrm{r}=0.58$ the hypothesis is confirmed. The scatter plot between two variables indicates that there was a positive and significant relationship between trust and mental models.

Sub-hypothesis 3: The relationship between trust and shared vision

As illustrated in Table 3, there is a positive correlation between trust and shared vision. Therefore, because P-value $=0.000<0.05, r=0.66$ the hypothesis is confirmed. The scatter plot between two variables indicates that there is positive and significant Relationship between trust and Shared Vision.

Sub-hypothesis 4: the relationship between trust and team learning

As illustrated in Table 3, there is a positive correlation between trust and team learning. Therefore, because P-value $=0.000<0.05, \mathrm{r}=0.55$ the hypothesis is confirmed. The scatter plot between two variables indicates that there is positive and significant Relationship between trust and team learning. 
Sub-hypothesis 5: The relationship between trust and systemic thinking

As illustrated in Table 3, there is a positive correlation between trust and systemic thinking. Therefore, because $\mathrm{P}$-value $=0.000<0.05, \mathrm{r}=0.63$ the hypothesis is confirmed. The scatter plot between two variables indicates that there is positive and significant Relationship between trust and systemic thinking.

Main hypothesis: The relationship between trust and learning organization

As illustrated in Table 3, there is a positive correlation between trust and learning organization. Therefore, because P-value $=0.000<0.05, r=0.73$ the hypothesis is confirmed. The scatter plot between two variables indicates that there is positive and significant Relationship between trust and learning organization.

\section{Conclusions and recommendations}

As mentioned, the new organizations are based on new knowledge, this means that they should be designed to use from new information and ideas and their staff be experts in the fields of expertise. Studies show that each member of organization must constantly learn new topics and able to identify and solve problems in their areas of activity rather than just trying to increase the efficiency. The experts believe that trust can lead to collaboration between individuals, groups and organizations. Today, organizations seeking new ways to enhance cooperation between individuals and groups will need to consider how to strengthen the trust more than every time. The results of various studies show that trust is one of the factors for success in changing environment and trust-building environment is necessary for organizations that are looking to learn. It should be noted that several forces could hinder the development of trust between members and within organization. In this paper, we have reviewed the barriers to establishing trust; If organizations are going to achieve success on the field they should know the potential barriers for establishing trust and appropriately manage them.

The recognition of these obstacles and minimizing their impact through creativity and leadership skills will increase trust and will lead to success of leaders and their organizations regularly. The results of this study showed that there was a significant relationship between trust and personal mastery. In this regard, we recommend the following,

Firms must create mechanisms for learning from failure and mistakes; encourage acceptance of responsibility or accountability; strength the professional competencies of employees and build selfconfidence among them. They also need to identify and use of opportunities.

In addition, the results of this study showed that there was a significant relationship between organizational trust and mental models. In this regard, creating incentive structure for creativity and innovation; mobilizing minds of employees through brainstorming and Delphi techniques; replacing strict control mechanisms with self-control and teamwork; establishing mechanisms for intelligent experiences are recommended. The results of this study showed that there was a significant relationship between organizational trust and shared vision. In this regard, application of group knowledge in organizational strategies; identifying and summarizing the experiences of employees and managers and transfer to other staff; aligning employee's goals and needs with aspirations of communities and organizations are recommended. The results of this study showed that there was a significant relationship between trust and team learning. In this regard, providing facilities for free and frank dialogue among employees and managers; involving employees in the executive program; job design with modern methods and the use of flexible work patterns; using new and flexible models in organizing are recommended. In addition, the results of this study showed that there was a significant relationship between organizational trust and systemic thinking. In this regard, 
simultaneous attention to the quality and quantity of services; periodic review of undertaken activities and using from resulting feedback; giving priority to modify communications and human resources development; continuous assessment of the economic, social and global circumstances, and investigate their effects on organizational activities are recommended.

\section{References}

Argyris, C., \& Schön, D. (1995). Organizational learning: A theory of action perspective, 1978. Massachusetts: Addison-Wesley Publishing Company.

Atkinson, S., \& Butcher, D. (2003). Trust in managerial relationships. Journal of Managerial Psychology, 18(4), 282-304.

Davenport, T. \& Prusak, L. (1998). Working knowledge. Boston: Harvard Business School Press.

Dodgson, M. (1993). Organizational learning: a review of some literatures. Organization studies, 14(3), 375-394.

Ellinger, A. D., Ellinger, A. E., Yang, B., \& Howton, S. W. (2002). The relationship between the learning organization concept and firms' financial performance: an empirical assessment. Human resource development quarterly, 13(1), 5-22.

Fairholm, M. R., \& Fairholm, G. (2000). Leadership amid the constraints of trust. Leadership \& Organization Development Journal, 21(2), 102-109.

Fazel, A., Kamalian A. R., Khojasteh G. R., \& Fazel, A. (2011). The role of trust in organizational innovation: a research in Iranian organization on service sector. Process Management and Development, 77, 72-89. [In Persian].

Fiol, C. M., \& Lyles, M. A. (1985). Organizational learning. Academy of management review, 10(4), 803-813.

Garvin, D (1993), Building a learning organization, Harvard Business Review, Aug.

Harvey, C., \& Denton, J. (1999). To come of age: the antecedents of organizational learning. Journal of Management Studies, 36(7), 897-918.

Hsieny, L. (2004). A study of learning organization and faculty development in higher education. Umipro. DAL- A65102. P 430. Aug.

Lawrence, E. (1998). Some thoughts on turning a government organization into a learning organization. Public service commission. http://www. psccfp.qc.ca/research/knowledge/learning.e org.htm.

Marquardt, M. J. (1996). Building the learning organization. McGraw-Hill Companies.

Nekooie-mogaddam, M., \& Beheshtifar, M. (2006). Learning Organizations, Parsa Publishing. [In Persian]

Neefe, D. O. (2001). Comparing levels of organizational learning maturity of colleges and universities participating in traditional and non-traditional (academic quality improvement project) accreditation processes. University of Wisconsin stout Menomonie, 5.

Panahi, B. (2009). Trust and trust building in organization, Peyke Noor, 7(4), 88-103.[In Persian]

Rahmanseresht, H. (2007). Theories of organization and management from modernism to Post modernism (period of Modernism), Tehran, period Publishing. [In Persian].

Rahnavard, F. A. (1999). Organizational learning and the learning organization. Journal of Applied Science and Public Administration. 43, Tehran, Public Management Training Center [In Persian].

Senge, P. M. (2006). The fifth discipline: The art and practice of the learning organization. Random House LLC.

Shafieai, A. (2011). Investigate the relationship between organizational trust and human resource productivity in Gowah company, MS Thesis, Tehran University [In Persian].

Sharifi, A., \& Eslmiyeh F. (2008). An investigation on the relationship between organizational learning and use of information and communication technologies in university of GARMSAR, new approach. Journal in the Educational Management, 2, 22-31. [In Persian].

Sharman, C. (2005). Leadership and the learning organization. UMI Proquest Digital Dissertation, State university of New York Empire state college. 